\title{
What We Can Learn About Business Modeling From Homeostasis
}

\author{
Gil Regev ${ }^{1,2}$, Olivier Hayard ${ }^{2}$, Alain Wegmann ${ }^{1}$ \\ ${ }^{1}$ Ecole Polytechnique Fédérale de Lausanne (EPFL), School of Computer and \\ Communication Sciences, CH-1015 Lausanne, Switzerland \\ \{gil.regev, alain.wegmann\}@epfl.ch \\ ${ }^{2}$ Itecor, Av. Paul Cérésole 24, cp 568, CH-1800 Vevey 1, Switzerland \\ \{g.regev, o.hayard\}@itecor.com
}

\begin{abstract}
Business modeling methods most often model an organization's value provision to its customers followed by the necessary activities and structure to deliver this value. These activities and structure are seen as infinitely malleable; they can be specified and engineered at will. This is hardly in line with what even laymen can observe of organizations, that they are not easy to change and that their behavior often is not directly centered on providing value to customers. Homeostasis is an almost century old model that was developed in the field of physiology to explain how living beings survive by maintaining the constancy of their internal states. Homeostasis helps to explain both the inability of organizations to provide maximum value to their customers and their reluctance to change. From this point of view, resistance to change is not something to fight or to ignore but an essential force behind organizational behavior that can either enable or defeat new business models.
\end{abstract}

Keywords: Business Models, Business Modeling, Survival, Systems, Identity, Homeostasis, Entropy, Negentropy.

\section{Introduction}

Business modeling refers to the description of organizations for the purpose of understanding their informational needs. The premise of business modeling is that IT needs to support the organization and it is therefore crucial to fully understand it [20]. Business modeling often begins by modeling the business processes of the organization and proceeds down the hierarchy to the way these processes are supported by the IT. In this view, business modeling provides a description, as complete as possible, of some part of the organization that needs IT support.

Business modeling also refers to the modeling of organizational strategy through initiatives such as Service Science [22] and frameworks such as e3value [7] and the Business Model Ontology [13]. A business model in these latter frameworks describes how a company provides and captures value [13]. In this paper we show that the concept of homeostasis is applicable to both business models and business modeling. Business models describe the interactions of the organization with its 
environment whereas business modeling enables to describe how these interactions are implemented within the organization. Likewise, homeostasis describes how an organization maintains internal constant states in order to become independent of environmental perturbations.

Homeostasis was developed in the field of physiology by Walter Cannon [2] to describe the survival of humans and animals in a changing environment. Homeostasis served as the basis for the development of cybernetics by Wiener and Rosenblueth [4]. Cybernetics, or the theory of control, is at the heart of all modern management theories and therefore of business models and business modeling. However, as explained by Weinberg and Weinberg [24] cybernetics is a less general principle than homeostasis. Cybernetics popularized the concepts of feedback, goal and aim, whereas homeostasis provides a much more general perspective about maintaining constancy.

Homeostasis, for example, explains organizational behavior better than current business modeling frameworks. All these frameworks tell us that a business model describes how value is delivered to customers and how it is captured by the organization. This focus on value does not explain the small print in contracts that by and large protects the organization more than it protects the customer. The escalating measures taken by organizations against customers who fail to pay their bills remain unexplained too. These aspects can be explained by the simple fact that an organization has to survive before it can provide value to its customers. Homeostasis explains these aspects by showing that the constancy of the internal states is paramount to every surviving organization. Organizations will take escalating measures to maintain this constancy, even at the risk of reducing the value they provide to customers.

Hence, returning to the roots of cybernetics, i.e. homeostasis and the maintenance of constancy, we can point to aspects of business models and business modeling that need to be researched in the future.

In Section 2 we describe some related work on business models and business modeling. In Section 3 we explain the concept of homeostasis and the related concepts of identity and internal environment. In Section 4 we formulate some suggestions for applying homeostasis to business models and business modeling. We summarize the paper and propose insights into future research in Section 5.

\section{Related Work - An Overview of Business Modeling}

Business modeling, enterprise modeling, enterprise architecture and enterprise engineering are used somewhat interchangeably to mean models of how an organization functions. Business modeling has emerged from the Information Technology (IT) practice as a way for IT people to understand the business's information needs. One of the early IT frameworks that integrate some aspects of business is what came to be called the Enterprise Architecture Framework, the Information Systems Architecture Framework, or more commonly the Zachman Framework [26]. Zachman's framework is made of a matrix in which the rows represent entities and the columns represent questions about these entities (e.g., what, 
how, when, why, where). The two topmost rows of Zachman's matrix represent the entities that are important to the business, the actions (processes) that it implements and the business locations in which it is present.

Sowa and Zachman define a business model as [21]: the "design of the business" that shows "the business entities and processes and how they interact." From the architecture perspective inherent in this framework, a business model is seen as [21]: "the architect's drawings that depict the final building from the perspective of the owner, who will have to live with it in the daily routines of business."

The Reference Model of Open Distributed Processing is an ISO/IEC standard for describing organizations, their informational needs and their IT support [9]. It consists of five viewpoints on the business: Enterprise, information, computational, engineering and technology [10]. The enterprise viewpoint captures the purpose, scope and policies of the organization [10].

ArchiMate is a more recent enterprise architecture method, which models business processes and their support by IT. ArchiMate defines business systems as dynamic systems. A dynamic system is described by active structure concepts (also called agents), passive structure concepts (also called patiens) and behavioral concepts [12]. ArchiMate is made of three layers called Business, Application and Technology [12]. The business layer describes business actors and roles performing business processes that deliver products and services to external customers. The application layer describes the support provided by software applications to the business layer. The technology level describes the infrastructure necessary to run the software applications [12].

The Design \& Engineering Methodology for Organizations (DEMO) is a methodology for literally engineer organizations [5]. Organizations are said to be "designed and engineered artifacts" much like cars and IT systems but with the exception that their "active elements are human beings in their role of social individual or subject." [5]. In DEMO the essence of the enterprise are transactions consisting of production acts and coordination acts between the subjects. With production acts the subjects create the "goods or services delivered to the environment." With coordination acts the "subjects enter into and comply with commitments toward each other regarding performance of P-acts Examples of C-acts are "request," "promise," and "decline."," [5].

Methods for defining business models include e3value and the Business Model Ontology.

e3value focuses on the exchange of value objects between economic actors [7]. The organization is viewed only as a black box. e3value has been linked with $i^{*}$, a leading Goal Oriented Requirements Engineering method [8]. Value and goal models are used to show the value activities that contribute to the enterprise goals [8].

The Business Model Ontology, BMO, [13] provides multiple ways of defining business models. Osterwalder and Pigneur define the concept of business model as [13]: "the rationale of how an organization creates, delivers and captures value." BMO proposes a canvas containing 9 elements: Customer Segments, Value Propositions, Channels, Customer Relationships, Revenue Streams, Key Resources, Key Activities, Key Partnerships and Cost Structure [13]. Osterwalder and Pigneur [13] describe a number of business model patterns and show how they can be described in the canvas. BMO focuses on the strategy formulation level and doesn't 
have an architecture component. The execution of the business model stops at the definition of the key resources and partnerships. More recently, work is underway [6] to couple BMO and ArchiMate in order to provide a more complete business layer for ArchiMate and to more finely define the execution of BMO business models.

In business modeling, it is assumed that the structure of the organization is defined once the value proposition has been defined. In other words, structure follows strategy. But structure, as Mintzberg et al. put it [11]: "follows strategy like the left foot follows the right" meaning that it is structure that enables strategy and strategy that changes the structure. Hence, without a firm structure of some kind, no strategy is possible. But where does structure comes from and how is it maintained? This is the subject of the following section.

\section{Homeostasis Explained}

Cannon coined the term Homeostasis in the 1920s to explain [2]: "how the human body reacts to disturbance and danger and maintains the stability essential to life." Cannon explains in [1] that he chose the term homeo, which means "like" or "similar" rather than homo, which means "the same" because homeo admits some variation rather than fixed rigidity. The term stasis is a reference to concept of statics in the branch of mechanics, where it means "a steady state produced by the action of forces." [1]. Cannon, however, preferred the term Homeostasis to Homeostatics so as to account for the physiological mechanisms that are far more complex than what he termed "simple mechanics" [1].

Cannon also envisioned that the same mechanisms that the human body uses to survive in exacting environments might also be applied to the study organizations and societies. In this section we begin by explaining what we mean by remaining the same followed by an explanation of hemostasis.

\section{Survival - Remaining Alike}

Business models and business modeling are made in order to improve the chances of an organization's long-term survival. We have shown elsewhere that for an organization to exist, it needs to maintain a number of norms (states that remain stable or constant) for a set of observers [14-19]. A company such as Compaq, for example, existed for some 20 years (since 1982 until its acquisition by HP in 2002). Compaq existed because it maintained a number of norms that customers, shareholders, suppliers, employees, competitors and others could see as identifying the organization called Compaq. When Compaq was acquired by HP most of its constituent elements, e.g. people, buildings, machines and even website, continued to exist but were not organized in a coherent whole that observers could identify and call Compaq. Instead, most of them were absorbed in a new structure called HP with different relationships giving them a different meaning for observers.

Drawing an analogy with biological phenomena, we can say that a company that is being acquired by another is quite similar to a mouse being eaten by a cat. The mouse 
maintains a relatively independent existence and as observers, we can identify it as a mouse. If it is caught and eaten by a cat, none of its constituent elements have disappeared, but the relations that they had, which made a whole that we could identify as a mouse, have been altered so that we cannot see the mouse anymore.

Whether it is a company or a mouse, from this general systems point of view, the process is the same. An organized entity that can be identified as a whole, having some integrity, is swallowed by another and cannot be identified as this whole anymore.

The concept of an open system explains the threats and opportunities posed by the environment to the organization [14-19]. An open system draws energy from its environment in order to decrease its entropy. Negative entropy (Negentropy) is a measure of order. In a world governed by the second law of thermodynamics, any closed system will move toward positive entropy, i.e. disorder. To maintain order an open system draws energy from its environment. In terms of our discussion above, this means that organizations exchange goods, services, ideas and money with their environment in order to maintain their internal relationships in specific states so that their stakeholders identify them [14-19]. Organizations, therefore, must establish relationships with other organizations [14-19]. These relationships are necessary but also potentially harmful [16]. Compaq, for example, had to have relationships with its competitors, which opened the door for its acquisition by HP.

To survive as an independent entity, therefore, the organization as much as the animal, must protect itself from threats to its organized whole. Not all of these threats come in the form of a cat or a buyout. The organization must protect itself from many threats, most of which may look benign (consider Amazon's threat to Barnes and Noble or Borders in 1995).

\section{The Internal Environment}

Cannon's work was largely based on Bernard's work [24, 4]. Bernard first defined the concept of "internal environment" to explain the independence of warm-blooded animals from environmental influences. Cannon quotes Bernard as saying [1]: "all the vital mechanisms, however varied they may be, have only one object, that of preserving constant the conditions of life in the internal environment." For Bernard, constancy of the conditions of life was made possible by the fact that the "internal environment comes less into equilibrium with the external cosmic environment" [24]. Weinberg and Weinberg explain that the same principles apply to systems in general. A company can be analyzed in terms of its internal environment (employees, machines, materials and other assets) being protected from the external environment (competitors, regulators, clients, suppliers). As expressed by Weinberg and Weinberg [24]: "As Bernard observed, this protection is not absolute, but merely makes it less easy for the internal environment to come into equilibrium with the exterior."

Cooper [4] quotes Haldane, as saying that: "In another sense, however, physiological activity is constantly disturbing the internal environment. What is actually maintained is a dynamic balance between the disturbing and restorative activities" 


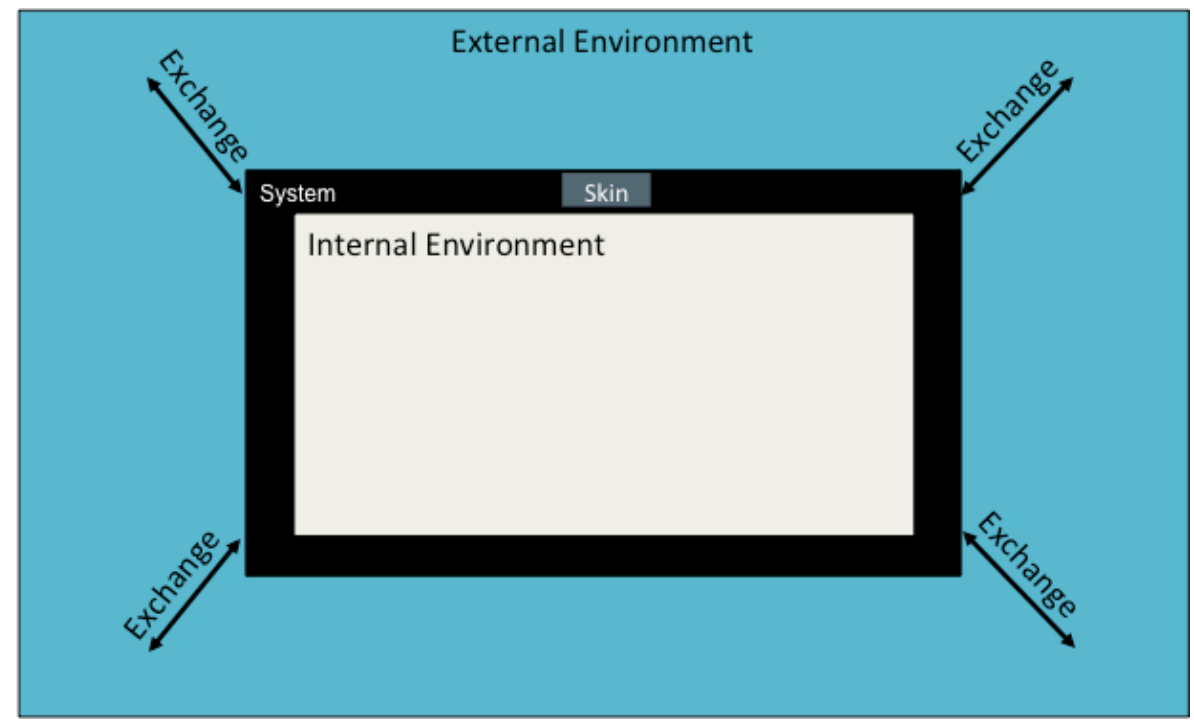

Figure 1. Internal and external environments

Cooper [4] describes this search for constancy of the internal environment and the responses to disturbances as resulting in disturbances that are kept within narrow limits through automatic adjustments: "The highly developed living being is an open system having many relations to its surrounding. [..] Changes in the surroundings excite reactions in this system, or affect it directly, so that internal disturbances of the system are produced. Such disturbances are normally kept within narrow limits, because automatic adjustments within the system are brought into action, and thereby wide oscillations are prevented and the internal conditions are held fairly constant."

In Figure 1, we illustrate this relationship between the internal and external environment. The open system represented as the rectangle in the middle of the figure has an internal environment that has exchanges with the external environment

\section{Homeostasis and Freedom of Action}

Human beings are made of a myriad of single cells, which together form a human individual with a specific identity. An independent single cell organism, Cannon [2] notes, usually lives in a water stream and depends completely on this stream of fluid from which its takes all its food and into which it excretes all its waste. The constancy of the stream is therefore of extreme importance for this cell. Without this constancy, the cell will starve or will be clogged by its own waste. The single cell cannot leave the stream on which it depends and therefore has very limited freedom of action. In a human body, the same principles apply. Cannon [2] explains that each single cell in our body is dependent on what he calls the "fluid matrix" for its continued existence. The fluid matrix is made of the blood and lymph streams. Together these two streams bring all food and oxygen to each individual cell in our body and remove all its waste. Cannon [2] further notes that almost all our cells are covered in a dry envelope that 
separates the internal streams in which these cells bathe from the air. The cells that are not covered in skin, e.g. our eyes and inner parts of our mouths and nose are bathed in salty water.

The individual existence of the cells in the body and, therefore, the survival of the body as a whole depend on the ability of the fluid matrix to constantly provide food and remove waste. The fluid matrix must therefore maintain many constant states, such as the blood pressure, salinity, calcium and sugar. Whenever one of these states strays away from its defined constant state, the body takes measures to restore this state.

This constancy of internal environment enables the body as a whole to become more independent of its external environment as compared with the single cell. Whereas the single cell cannot stray outside the stream it lives in, human beings can wander quite far from streams. They can live in external environments as different as the arctic or the Sahara. Between the single cell organism and mammals, there are a variety of organisms that only partially maintain stable internal states. Frogs, for example, cannot hold water as much as mammals can and therefore cannot move too far from a stream albeit more than single cell organisms. Similarly, the ability of mammals to tightly control their body temperature enables them to be active in external environments and conditions where reptiles become inactive. Whereas reptiles need external sources of heat or cold, e.g. the sun to warm them up and water to cool them down, mammals can rely on their internal environment to produce the necessary heat or to cool the body down.

Within the stream, the single cell organism can move about and do whatever it likes. In a body, however, an individual cell does not possess the same freedom. As described by Cannon, in the body, each cell is specialized in a given role and is fixed in a given location. This specialization and location are crucial for the body to function as a whole. Cells that specialize and have a fixed location are dependent on the fluid matrix for the continued existence because they are far removed from the food source. Hence, the individual cell and the organism are interdependent [2].

\section{The Six Propositions of Homeostasis}

Cannon [1] defines six propositions for explaining homeostasis:

"1. In an open system, such as our bodies represent, compounded of unstable material and subjected continually to disturbing conditions, constancy is in itself evidence that agencies are acting or ready to act, to maintain this constancy."

" 2 . If a state remains steady it does so because any tendency towards change is automatically met by increased effectiveness of the factor or factors which resist the change."

"3. Any factor which operates to maintain a steady state by action in one direction does not also act at the same point in the opposite direction."

"4. "Homeostatic agents, antagonistic in one region of the body, may be cooperative in another region."

"5. The regulating system which determines a homeostatic state may comprise a number of cooperating factors brought into action at the same time or successively." 
" 6 . When a factor is known which can shift a homeostatic state in one direction it is reasonable to look for automatic control of that factor, or for a factor or factors having an opposing effect."

For Weinberg and Weinberg [24] proposition 1 is a general statement that draws our attention to the fact that in a changing environment, behind every constant state there are mechanisms that act against change. It refers to the ubiquity and never ending nature of regulatory mechanisms. It reminds us that we need to investigate how each entity we observe is maintained constant.

Proposition 2 according to Weinberg and Weinberg [24] tells us to look for activities that maintain this constancy, or in Weinberg and Weinberg's words [24]: "In the search for the source of constancy, look for activity." Not only should we look for activities, but we should also expect increased effectiveness of these activities when they oppose change.

Propositions 3 and 4 describe mechanisms that are both cooperative and antagonistic in different regions of the body. This makes us appreciate the complexity of the mechanisms that the body can bring into effect in order to maintain constancy.

Proposition 5 tells us to look for multiple mechanisms and not stop when we found only one [24]. A homeostatic system brings together multiple mechanisms, each having a specific state to maintain constant.

Proposition 6 according [24] and [1] is already contained in the other propositions. It makes us look for an automatic control of each mechanism [24]. It also draws our attention to mechanisms that have opposite effects from one another [24]. These are mechanisms that counter the counter of change. These opposing mechanisms can be quite confusing. They act against each other in ways that often seem to us to be at odds or to be inconsistent. Their overall effect, however, is to ensure that the state controlled by the homeostatic system does not stray outside the narrow limits.

Because homeostasis is such a ubiquitous phenomenon in enduring organizations and because business modeling is ultimately concerned with creating enduring organizations, homeostasis has a very large applicability to business modeling. In the next section we outline some aspects that can be used in future business modeling methods.

\section{Homeostasis for Business Modeling}

As we have seen above, Cannon speaks in very general terms about open systems that are subject to external perturbations and are made of instable components. He takes the human body only as an example. Hence, Weinberg and Weinberg [24] note that homeostasis is a very general and useful heuristic device organizations of any kind.

Cannon [2] envisioned that homeostasis should be applicable not only to humans and animals but also to organizations and societies. He conjectured that organizations and societies too depend on stable states. In a society, individuals who used to be generalists (i.e. hunter gatherers, farmers) have, through the industrial revolution, specialized and thus have become far from the sources of food. To survive, these specialists that we all are need the constancy of society's fluid matrix. 
The same can be said of organizations and their employees. Organizations can be studied as open systems subject to external perturbations and made of unstable components. An organization survives, as we have seen, if it maintains some states within narrow limits for an observer. The constancy of these states depends on the constancy of the internal environment, which in turn depends on narrow limits enforced on the exchanges with the external environment. To be closer to the business modeling literature, we will use the terms norms and tolerances proposed in [17] for the stable states and the narrow limits imposed on them.

We first examine the exchanges with the external environment, and then turn to the internal environment.

\section{Business Models - Exchanges with the External Environment}

As we have seen, a business model is said to describe how a company delivers and captures value to its customers. Notice, however, that in Cannon's description of homeostasis there is no mention of customers but only of disturbances. There is no implied hierarchy in the relationships between an open system and its external environment. Analyzing an organization as an open system leads us to generalize the narrow notion of the exchange of value with customers into the interactions between the organization and all its stakeholders.

In Figure 2 we illustrate the exchanges between an organization and its stakeholders. This is a specialization of the model shown in Figure 1. The exchanges between the organization and its external environment have been in general superseded with the exchanges between the organization and the standard stakeholders found in business models.

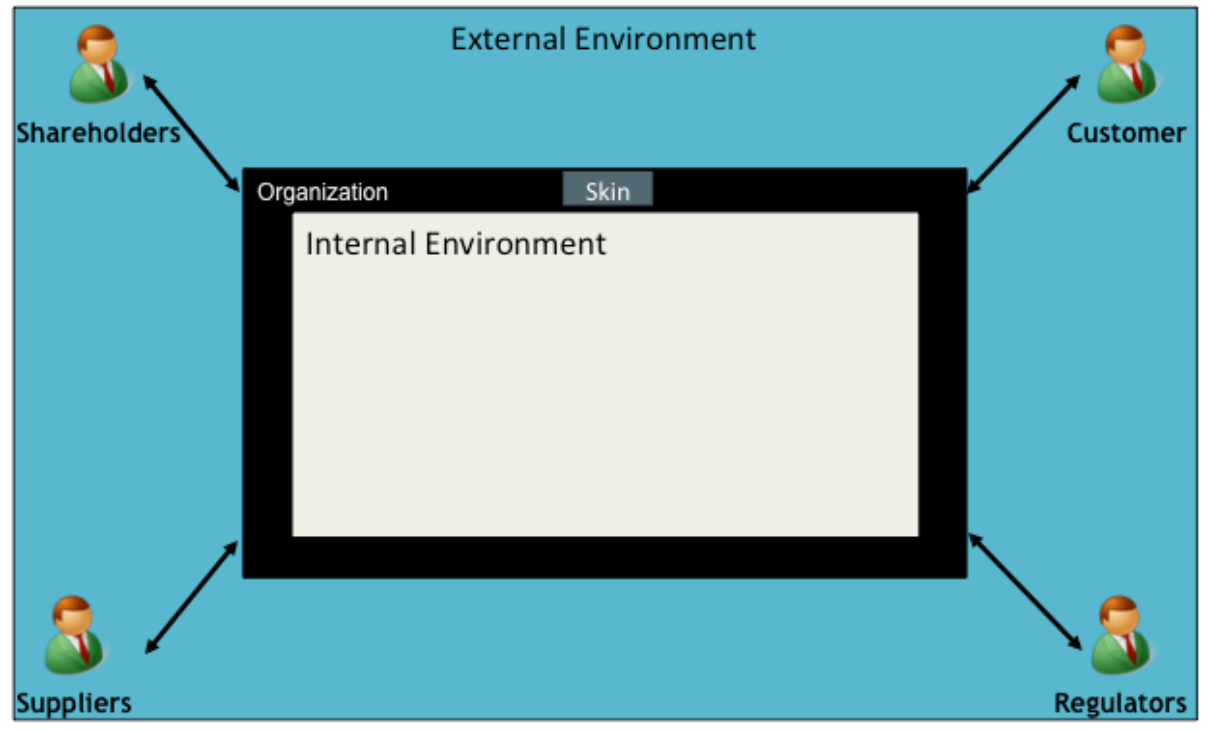

Figure 2. Internal and external environments in business models 
An organization, seen as an open system, needs a constant exchange with the stakeholders in its external environment. It needs constant inflow and outflow of information, energy, money and material. For the internal environment of the organization to be maintained within tolerance, these exchanges with the external environment must be kept within tolerance as well. Examples of the control exercised by organizations to maintain these exchanges within tolerance are abundant all around us. Warranty statements, sales conditions, contracts and the like all contain rules that protect the organization and place "narrow limits" on what it accepts to exchange with customers.

Insuring a revenue stream, for example, drives companies such as banks and mobile phone operators, to provide better service to customers who bring large revenues (premium customers). Just providing value to customers is not the main point. It is rather insuring a steady or steadily increasing revenue stream. Maintaining a steady revenue stream also explains why it is the organization that usually fixes the price of the products and services it provides rather than the customer. If companies were only interested in providing value to customers, they would give their products and services for free, or they would allow customers to define the price. But because they need to maintain their internal environment constant in order to provide the products and services and because this maintenance has a certain cost, they cannot allow the customer to define the price they want to pay. This is true for all other sales conditions, not only for the monetary exchange. The same analysis can be made about the relations of the organization with its suppliers, shareholders and regulators. Contracts and incoming inspections of material coming from suppliers, for example, limit what the organization accepts to exchange with suppliers. Lobbying and participation in trade associations limit the exchanges with regulators.

The tolerances on the exchanges with the stakeholders should not be seen as having only lower limits (e.g. as when the revenue stream slows down). They also have upper limits. A company that is subject to a large influx of customers in a very short time can also feel the threat to its internal environment and take actions to limit this flow. It may separate between customers that it wants to keep and those that it does not. Thereby maintaining the states that it deems important (level of quality, number of employees) unchanged. The value to these unwanted customers may be described as negative. We see that the homeostatic system does not necessarily maximize value for a given customer.

It is the internal environment that compensates for changes in the exchanges with stakeholders that are out of tolerance. For example, customers who don't pay their bills on time are outside the tolerance defined by the due date for the payment. The problem for companies is to make sure that their treasury is sufficient to pay their employees, suppliers etc. When customers do not pay on time, it can limit the possibility for the company to pay its own bills. It is the actions of people from inside the organization that can bring the customers to pay their bills. Therefore, any business model is dependent on the constancy of the internal environment and the internal environment is dependent on the constancy of exchanges afforded by the business model. 
The freedom of action of the organization, its ability to implement new business models, depends on the constancy of its internal environment in the same way that the constancy of mammal body enables it to have more freedom of action than reptiles.

In summary, business models should be extended with the following aspects:

- The exchanges with all stakeholders

- The tolerances placed on these exchanges

- The actions the organization is ready to take to enforce these tolerances

- The constancy of the organization's internal environment and its ability to support a new business model

\section{Business Modeling - the Internal Environment}

The essence of business modeling should be understood as representing the constancy of internal environment of the organization. This is often done by placing concepts within a container, as in Figure 3. Unlike the human body, the organization doesn't have a real skin that separates the internal and external environment. The skin in Figure 3 is therefore an analogy for the body's skin [24]. The skin represents the protection afforded by the organization to people and objects within its internal environment. As we have seen above, this protection is not absolute. It simply makes it less easy for the inside of the organization [24] "to come into equilibrium with the exterior." The business rules, terms of use, conditions of sale, contracts internal rules, business processes and the like that organizations impose on their suppliers, members and customers are the visible part of the protection offered by this "skin". They are designed to protect the inside of the organization from what it considers to be unstable relationships inside and outside the organization.

The internal environment is made, as described by Cannon, by unstable material. These are departments, people, machines, buildings and the like. They belong to the internal environment of the organization just so long as the organization is able to maintain the constancy of the equivalent of the fluid matrix described by Cannon. In analogy to the body's fluid matrix, the organization's fluid matrix brings all the food to, and removes all the waste from, its members. Whereas Cannon's fluid matrix was made from the blood and lymphatic streams, the organization's fluid matrix is made from the flow of information, energy, material and money. If any one of these flows stops or even slows down below some tolerance level, all other flows will stop too and the organization will cease to exist. A simple example is a company that cannot pay its employees, that cannot maintain its machines or buildings or that cannot remove waste from its manufacturing plant. The result will be a dismemberment of the company. This can take more or less time depending on how far things have wandered from the tolerances that allow maintaining the constancy of other flows. If money is not paid to employees, they will quickly stop all other flows of information, energy and material. Likewise, if waste is not removed from a manufacturing site, it will pile up within the company and end the flow of products will eventually stop. It may very well be that building maintenance and waste removal will take more time to stop the flow than the lack of salary payment to employees but if action is not taken to remedy the situation, ultimately the result will be the same. 


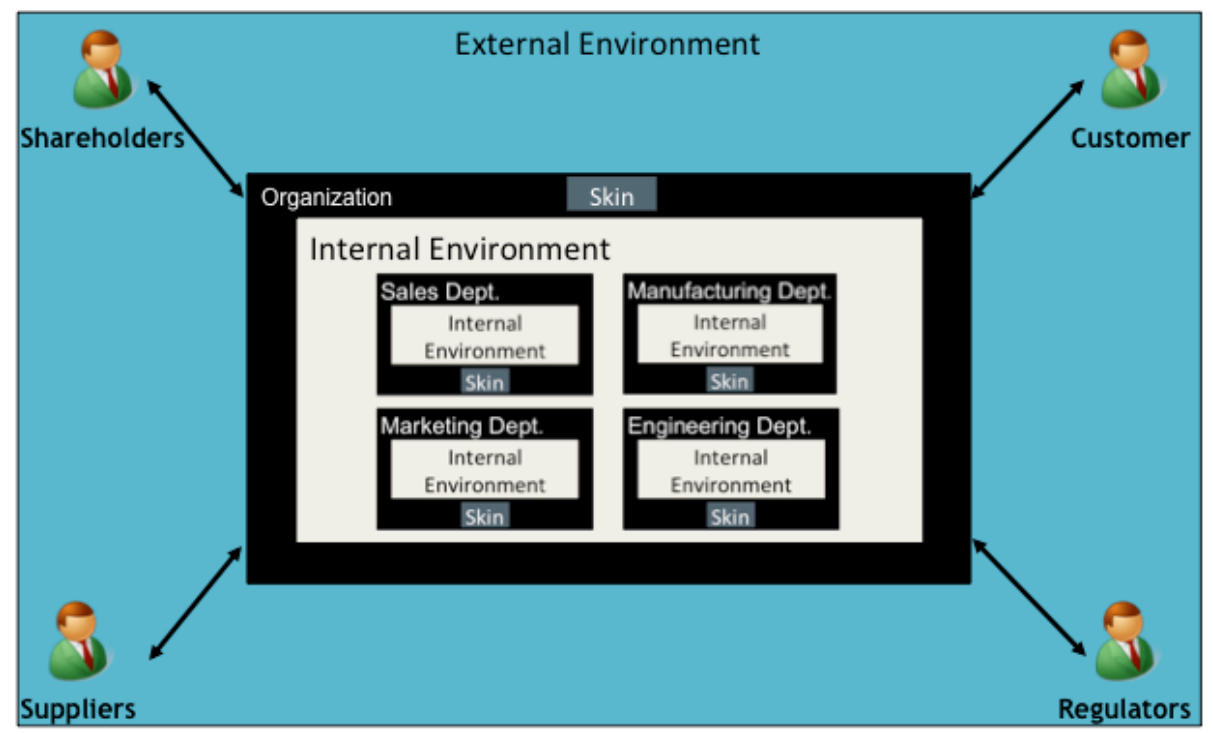

Figure 3. The internal environments of departments within an organization

The mechanisms described in Cannon's propositions, provide ways of understanding how the necessary constancy of these flows is maintained. If the situation of the organization doesn't deteriorate over time it is because the many activities are undertaken to maintain the constancy of its internal environment. When the revenue or profit of a company decline below expectations (below tolerance) many actions will be taken at the same time or successively in order to reduce cost, increase sales, increase research and development, warn shareholders to lower their expectations, freeze hiring, renegotiate credit, layoffs etc. Some of these actions may ignite other actions from other stakeholders, such as strikes and demonstrations by employees, intervention by political authorities, takeover by competitors and the like.

Each department or group of people within the organization will attempt to maintain the constancy of its own internal environment. It will likely take all the activities described by Cannon to defeat a change that is outside the tolerance that its internal environment relies on. This, in turn, means that some of its activities will not be aligned with the overall organization's needs. Remember Cannon's propositions 3 and 4 that describe activities antagonistic in one area and cooperative in other areas. This antagonistic and cooperative nature of activities is often confused by observers as being dysfunctional whereas it may simply be the normal action of a homeostatic system attempting to maintain constancy. Therefore, total alignment inside or outside the organization, as sought by Enterprise Architecture methods is not even an idealized situation but a non-desired situation. Because we want our models to be as accurate as possible, it is useful to model these homeostatic mechanisms.

This automatic control described in Cannon's proposition explains, in part, why we often do not see homeostatic mechanisms. When some state is controlled automatically, by definition, no conscious control is needed. Hence, most homeostatic 
mechanisms are applied without us even being aware of them. They have been internalized and made tacit [23]. Often, it is only when they fail that we become conscious of them, as shown in [25]. Therefore, just like in our bodies, the automatic compensation afforded by homeostasis makes constancy a given.

Business modeling is often done with some change in mind. We make a model of the organization as it is today (the as-is model) and the way we want it to be in the future (the to-be model). Modeling the homeostatic mechanisms can be useful in both cases. For the as-is model this would explain what makes the organization or some part of it constant. For the to-be model it would explain how to make it constant. The transition from the as-is model to the to-be model must take into account the homeostatic reactions both for and against this change. The obliviousness of homeostatic systems for the goodness or badness of the constancy they maintain often results in frustration by change agents. For a homeostatic system, every change is a threat, not an opportunity. An opportunity is necessarily a change to a state kept constant by the homeostatic system and is therefore an unwelcome occurrence. In other words, a homeostatic system does not distinguish right from wrong. It only maintains some state constant. It doesn't care whether maintaining this constancy is good or bad. Weinberg and Weinberg describe this property of homeostatic systems as [24]: "The same mechanisms that prevent us from being poisoned also prevent us from being medicated." The new business model that may be able to save the company can be effectively diffused by the homeostasis of the internal environment. Hence, from the point of view of some observer, the homeostatic system's ability to maintain constancy in the presence of change sometimes has positive results (as when it enables the implementation of a new business model) and sometimes negative results (as when it defeats this implementation).

Mature organizations have specialized departments that deal with each stakeholder group so as to insure that the exchanges with this group actually keep the exchange within tolerance.

In summary, business modeling should be extended with the following aspects:

- Identify how the intake from the external environment is distributed in the internal environment through flows of information, money, energy and material

- Identify the tolerances on these flows

- Identify how these flows are maintained constant through antagonistic and cooperative activities

- Add waste removal to business modeling frameworks

- Focus less on monetary exchanges and more on the everyday activities that maintain constancy

- Take the antagonistic and cooperative actions exhibited in the organization as attempts to maintain stability

- Identify implicit flows of information and the way they maintain constancy 


\section{Conclusions}

Business modeling methods take the underlying organization that is supposed to carry out a new business model for granted. They assume that the organization will either follow the defined strategy or that it can be engineered to fit the strategy. In essence they consider that the organization has an infinite capacity to change. This is overlooking the everyday observation that any organization that has been in existence for even a few years has built some very strong mechanisms that resist change.

Any surviving organization has adapted to a specific environment. It has built a dynamic balance between its external environment (customers, regulators, investors, competitors) and its internal environment. Changing this internal environment to fit a different external environment is quite difficult. Without taking this aspect into consideration, the probability of successfully implementing a new business model is very low. Business modeling must take this into account. Homeostasis is a heuristic device that provides a plausible explanation to the way organizations resist change in order to maintain their identity and therefore survive in a changing environment. We have shown that homeostasis can help both the formulation of Business Models and business modeling.

Homeostasis draws our attention to the importance of the internal environment, its constancy and its relationships with the external environment. Cannon's principles, although not detailed enough, provide a starting point for extending business modeling methods with modeling constructs that describe this constancy.

Taking homeostasis seriously is to accept inconsistencies rather than seeking alignment. From a homeostasis perspective inconsistency can be seen as a necessary mechanism to insure survival.

Modeling homeostasis does not mean that we consider that change is impossible, only that change is very hard to create and maintain. To institute change, the homeostatic system first must be neutralized. This is very hard to do without making the organization fragile.

Weinberg and Weinberg [24] point out that Cannon doesn't speak of goals and targets but rather about constancy. A homeostatic system, therefore, has no specific goal or target. It simply maintains some constancy with whatever number of mechanisms it can bring to bear. If we want to take homeostasis seriously, being that it provides such a good explanation of organizational life, we need to overcome our own homeostatic system and supplant the terms goals, targets, purpose, ends and means with search for constancy and how it is maintained.

In the business and IT alignment literature, [3] reports about paradoxes where too much alignment can be counter productive, and where misalignment in the form of Disagreement, friction, and conflict can lead to better business performance. [3] also notes that the business and IT alignment research lacks theoretical underpinning. Our work could serve as a starting point for more theory-based research in both business modeling and business and IT alignment. 


\section{References}

1. Cannon, W:B., "Organization for Physiological Homeostasis", In Physiological Reviews, Vol IX, No. 3, pp. 399-431, July 1929.

2. Cannon, W.B. The Wisdom of the Body, Norton \& Company, New York, 1939.

3. Chan, Y.E. and Reich, B.H., "IT alignment: What have we learned?" In Information Technology Vol. 22, pp. 297-315, 2007.

4. Cooper, S.J., "From Claude Bernard to Walter Cannon. Emergence of the concept of homeostasis" In Appetite Vol. 51, 419-427, 2008.

5. Dietz, J.L.G., "The Deep Structure of Business Processes" In Communications of the ACM Vol. 49, No. 5, 2006.

6. Fritscher, B. and Pigneur, Y., "Business IT Alignment from Business Model to Enterprise Architecture" In Busital 2011, 6th International Workshop on BUSinness/IT ALignment and Interoperability, LNBIP 83. Springer, 2011.

7. Gordijn, J. and Akkermans, J.M.,. "Value-based requirements engineering: exploring innovative e-commerce ideas" In Requirement Engineering. Vol. 8, No. 2, 114-134, Springer, 2003.

8. Gordijn, J., Yu, E. and van der Raadt, B., "e-Service Design Using i* and e3value Modeling", IEEE Software. Vol. 23, No. 3, 2006.

9. ISO/IEC 10746-1, 2, 3, 4 I. ITU-T Recommendation X.901, X.902, X.903, X.904. "Open Distributed Processing - Reference Model", 1995-98.

10. Kilov, H., Business Specifications: The Key to Successful Software Engineering, Prentice Hall PTR, 1999.

11. Mintzberg, H., Ahlstrand, B. and Lampel J., Strategy Safary - The complete guide through the wilds of strategic management. Prentice Hall, 1998.

12. Lankhorst, M.M., Proper, H.A. and Jonkers, H., "The Architecture of the ArchiMate Language".In BPMDS 2009 and EMMSAD 2009, LNBIP 29. Springer, 2009.

13. Osterwalder, A. and Pigneur, Y., Business Model Generation, 2010.

14. Regev, G. and Wegmann, A., "Defining Early IT System Requirements with Regulation Principles: the Lightswitch Approach" In RE'04, 12th IEEE International Requirements Engineering Conference, IEEE, 2004.

15. Regev, G. and Wegmann, A.,. "Where do Goals Come From: the Underlying Principles of Goal-Oriented Requirements Engineering" In RE'05 13th IEEE International Requirements Engineering Conference, IEEE, 2005.

16. Regev, G., Alexander, I. F. and Wegmann, A., "Modelling the regulative role of business processes with use and misuse cases" In Business Process Management, Vol. 11 No. 6, 2005.

17. Regev, G., Hayard, O., Gause, D.C. and Wegmann, A., "Toward a Service Management Quality Model” In REFSQ'09, 15th International Working Conference on Requirements Engineering: Foundation for Software Quality Springer, 2009.

18. Regev, G., Hayard, O. and Wegmann, A.,. "Service Systems and Value Modeling from an Appreciative System Perspective" In IESS1.1, Second International Conference on Exploring Services Sciences. Springer, 2011.

19. Regev, G. and Wegmann, A.,." Regulation, The Invisible Part of the Goal Oriented Requirements Engineering Iceberg” In BMSD 2011, 1st International Symposium on Business Modeling and Software Design. SciTePress, 2011.

20. Shishkov, B., Foreword,. ,In BMSD 2011, In BMSD 2011, 1st International Symposium on Business Modeling and Software Design. SciTePress, 2011.

21. Sowa, J.F. and Zachman, J.A., "Extending and formalizing the framework for information systems architecture" In IBM Systems Journal Vol. 31. No. 3, 1992. 
22. Spohrer, J, and Riecken, D., "Special issue: services science" In Communications of the ACM Vol. 49 No. 7, 2006.

23. Vickers, Sir G.,. Policymaking, Communication, and Social Learning, eds, Adams, G.B., Forester, J., Catron, B.L.,Transaction Books. New Brunswick NJ, 1987.

24. Weinberg, G. M. and Weinberg, D., General Principles of Systems Design, Dorset House, 1988.

25. Winograd, T. and Flores, F., Understanding Computers and Cognition: A New Foundation for Design, Ablex. Norwood, NJ, 1986.

26. Zachman, J.A., "A framework for information systems architecture" In IBM Systems Journal Vol. 26. No. 3, 1987. 